\title{
Analisa SWOT Kebijakan Poros Maritim Global di Wilayah Kepulauan Riau
}

\author{
Artha Yudilla ${ }^{1}$, Pahmi Amri ${ }^{2}$ \\ ${ }^{1}$ Program Studi Hubungan Internasional, Fakultas Ilmu Sosial dan Politik, Universitas Islam Riau \\ - Indonesia \\ ${ }^{2}$ Program Studi Ilmu Pemerintahan, Fakultas Ilmu Sosial dan Politik, Universitas Islam Riau - \\ Indonesia \\ Email: arthayudilla@soc.uir.ac.id
}

Submitted: 29 October 2020 | Accepted: 29 December 2020

\begin{abstract}
Geostrategic and geopolitical positions provide opportunities for Indonesia not only as a global economic path but also an international marine security pathway. Maritime wealth is also a force in Indonesia's maritime diplomacy in the International realm. This is then the basis of the formulated mega project policy to make Indonesia a global maritime axis. But the problem is that so far the Global Maritime Fulcrum policy does not yet have a detailed blueprint for policy implementation in the national state and only focuses on macro discussions in the form of international cooperation discourse that has also not seen significant progress. . This research will try to analyze how the Global Maritime Axis policy is implemented. What are strengths, weaknesses, opportunities, and threats. at the micro level. To be more specific, this research will take a case study in Riau islands which is one of the most strategic maritime areas in Indonesia located in the strait of Malacca. By analyzing how this policy is rationed directly in the micro realm can be a record for governments in formulating better policies in the future.
\end{abstract}

Keywords: GMF, Geopolitics, SWOT, Riau.

\begin{abstract}
Abstrak
Posisi geostrategis dan geopolitik memberikan peluang bagi Indonesia tidak hanya sebagai jalur ekonomi global tetapi juga jalur keamanan laut internasional. Kekayaan maritim juga menjadi kekuatan diplomasi maritim Indonesia di ranah Internasional. Hal inilah yang kemudian mendasari kebijakan mega proyek yang dirumuskan untuk menjadikan Indonesia poros maritim dunia. Namun yang menjadi persoalan, sejauh ini kebijakan Poros Maritim Global belum memiliki cetak biru yang rinci dan hanya fokus pada pembahasan makro berupa wacana kerja sama internasional yang juga belum menunjukkan kemajuan yang berarti. . Penelitian ini akan mencoba menganalisis bagaimana kebijakan Poros Maritim Global diterapkan. Apa itu kekuatan, kelemahan, peluang, dan ancaman. di tingkat mikro. Lebih spesifiknya, penelitian ini akan mengambil studi kasus di Kepulauan Riau yang merupakan salah satu kawasan maritim paling strategis di Indonesia yang terletak di selat Malaka. Dengan menganalisis bagaimana kebijakan ini diimplementasikan langsung di ranah mikro, diharapkan dapat menjadi catatan bagi pemerintah dalam merumuskan kebijakan yang lebih baik di masa depan.
\end{abstract}

Kata kunci: GMF, Geopolitik, SWOT, Kepri

\section{PENDAHULUAN}

Indonesia memiliki potensi kelautan yang menjadi sumber menjadi negara dengan ekonomi kemakmuran bagi masyarakatnya. 
Sebagai negara kepulauan terbesar menjadikan Indonesia memiliki potensi maritim dalam berbagai bidang tidak hanya sebagai kawasan bioteknologi dan wisata kelautan, perairan laut dalam dan mineral kelautan, tetapi juga industri pelayaran dan pertahanan serta industri maritim dunia. Selain potensi sumber daya alam tersebut, Indonesia juga diuntungkan oleh lokasi teritorial yang strategis secara politik maupun ekonomi. Indonesia berada di daerah ekuator, antara benua Asia dan Australia yang secara langsung menghubungkan ekonomi negaranegara maju. Selain itu, Indonesia juga terletak di antara dua samudera, Pasifik dan Hindia yang menjadikan Indonesia menjadi kawasan penghubung antarnegara di kawasan Asia Timur dan Asia Tenggara serta Asia Selatan. Beberapa selat strategis lalu lintas maritim global juga berada di perairan Indonesia yakni Selat Malaka, Selat Sunda, Selat Lombok dan Selat Makasar

Posisi geostrategi dan geopolitis tersebut memberikan peluang Indonesia tidak hanya sebagai jalur ekonomi global tetapi juga jalur keamanan laut internasional sehingga menempatkan Indonesia memiliki keunggulan sekaligus ketergantungan yang tinggi terhadap bidang kelautan. Sangat logis jika kemudian, ekonomi kelautan (kemaritiman) dijadikan tumpuan bagi rancangan pembangunan ekonomi nasional melalui gagasan Poros Maritim dunia yang disampaikan oleh Presiden Jokowi dalam KTT Asia Timur pada 13 November 2014 di Nay Pyi Taw, Myanmar.

Permasalahannya adalah sejauh ini kebijakan Poros Maritim Global belum memiliki blueprint yang detail terkait implementasi kebijakan di tataran nasional dan hanya fokus pada pembahasan makro berupa kerjasama internasional yang juga belum terlihat progress yang signifikan. Mega proyek seperti pelabuhan internasional, tol laut, dan sejumlah infrastruktruktur lainnya masih belum dapat direalisasikan dengan baik, oleh karena itu perlu dilakukan penelitian mendalam dengan metoda analisa kekuatan (strength), kelemahan, (weakness), peluang (opportunity), dan ancaman (threat). untuk mengetahui permasalahan terkait program di daerah yang menjadi fokus kebijakan, sehingga program yang lebih baik dapat dirumuskan di kemudian hari. Kepulauan Riau dipilih sebagai lokus penelitian karena wilayahnya yang strategis dan memiliki potensi maritim yang sangat besar.

\section{TINJAUAN LITERATUR}

Sebenarnya pasca dikelurakannya kebijakan mengenai Poros Maritim Global di tahun 2014, telah terdapat 
beberapa penelitian yang berkaitan dengan kebijakan ini, diantaranya "Kebijakan Geopolitik Poros Maritim di Era Jokowi dalam Filosofi Ideologi" oleh (Fathun, 2017) yang menjelaskan bagaimana satu kebijakan politik luar negeri dibentuk.

Dengan menggunakan teori geopolitik terkait pentingnya posisi geografi satu Negara, dapat disimpulkan bahwa faktor pendorong dirumuskannya kebijakan Poros Maritim Global adalah posisi strategis wilayah maritim Indonesia. Penelitian ini juga mencoba menjelaskan bahwa adanya tarik penarik kepentingan antar aktor pembuat kebijakan di level nasional yang akhirnya mempengaruhi arah kebijakan Poros Maritim Global Indonesia.

Analisa kekuatan nasional Indonesia untuk menjadi Poros Martim Global terdapat dalam tulisan "Indonesia National Power to Acbieve Global Maritime Fulcrum" (Saragih, Siregar, \& Putera, 2018). Penelitian ini menjelaskan Indonesia memiliki wilayah laut yang luas, kekayaan laut yang banyak, serta posisi yang strategis yang menjadi modal dasar untuk menjadi Poros Maritim Global, namun di sisi lain kekuatan angkatan laut juga harus ditingkatkan baik secara kualitas maupun kuantitas. Dan keterbukaan Indonesia untuk menjalin kerjasama baik secara bilateral maupun multilateran untuk menjadi
Poros Maritim Global dijelaskan dalam "Indonesia's Global Martime Fullcrum, Contribution in the Indo Pacific Region" (Aufiya, 2017)

Peluang dan tantangan Indonesia untuk menjadi Poros Maritim Global dijelaskan dalam "Indonesia's Global maritime Fulcrum, Challenges and Trajectories" (Institute of Defence and Strategic Studies, 2015) dimana dijelaskan bahwa meskipun secara geopolitik dan geostrategic Indonesia memiliki modal yang menjanjikan untuk menjadi Poros Maritim Global, namun pemerintah hanya membuat kebijakan yang bersifat makro tanpa blueprint yang jelas dalam tataran mikro.

Penelitian "Kebijakan Poros Maritim Jokowi dan Sinergitas Strategi Ekonomi dan Keamanan Laut Indonesia" (Al Syahrin, 2018), menjelaskan ketimpangan fokus ekonomi dan keamanan Negara. di satu sisi kebijakan Poros Maritim terkesan sangat ambisius dengan berbagai mega proyek infrastruktur, seperti tol laut dan pelabuhan pelabuhan internasional di beberapa wilayah strategis di Indonesia, namun di sisi lain sektor keamanan maritime Indonesia masih memiliki banyak masalah seperti illegal fishing, dan masalah perbatasan yang sampai sekarang belum dapat diselesaikan.

Penelitian lainnya berjudul 
"Toward Indonesia as Global Maritime

Fulcrum: Correcting Doctrine and Combating Non-Traditional Maritime Threats" (Hudaya, Putra, \& Putra, 2017) fokus pada ancaman yang menghambat terwujudnya visi Indonesia menjadi poros maritime global, terutama ancama non tradisional berupa pembajakan dan terorisme khususnya di wilayah perbatasan seperti selat Malaka, serta doktrin yang salah mengenai Negara kepulauna yang mengakibatkan selama ini Indonesia terlalu mengutamakan pembangunan darat dibanding laut .

Penelitian lainnya yang juga menyorot ancaman maritim Indonesia dijelaskan dalam "Menerjemahkan Visi Poros Maritim Global dalam Kerangka Diplomasi Pertahanan Maritim dalam Kebijakan Luar Negri di Era Jokowi”" (Laksmana, Gindarsih, \& Mantong, 2018) yang menegaskan bahwa kebijakan Poros Maritim Global belum memiliki startegi yang jelas untuk benar-benar menyelasikan permasalahan maritime di Indonesia.

Sedangkan bentuk diplomasi perbatasan Indonesia dijelaskan dalam "Indonesia Border Diplomacy under The Global Martime Fulcrum" (Ndika \& Tri, 2017). Indonesia memiliki batas maritim dengan sepuluh Negara yakni Australia, India, Filipina, Malaysia, Palau, Papua Nugini, Singapura, Thailand, Timor Leste, dan Vietnam.
Oleh karena itu perjanjian dengan bargaining position yang seimbang sangat dibutuhkan baik dala bentuk kerjasama maupun penyelesain sengketa perbatasan

Terlihat bahwa penelitianpenelitian sebelumnya hanya fokus pada tataran kontekstual, yang hanya menganalisa kebijakan secara teoritis dalam tataran makro, tanpa benarbenar menganalisa bagaimana kebijakan tersebut diimplementasikan dalam level nasional. Oleh karena itu penelitian ini memiliki perbedaan (state of art) yang cukup signifikan, karena berbeda dari penelitian sebelumnya, penelitian ini akan mencoba menganalisa bagaimana kebijakan Poros Maritim Global diimplementasikan. Apa saja kekuatan (strength), kelemahan (weakness), peluang (opportunity), dan ancaman (threat) (Humphrey, 2006). di level mikro.

Untuk lebih spesifik, penelitian ini akan mengambil studi kasus di wilayah Kepulauan Riau yang merupakan salah satu wilayah maritim paling strategis di Indonesia yang berada di kawasan selat Malaka. Wilayah ini merupakan kekuatan maritim Indonesia dan memiliki bargaining power yang besar bagi diplomasi maritim Indonesia untuk menjadi Poros Maritim Global. Maka dengan menganalisa bagaimana kebijakan ini dijawantahkan langsung 
di ranah mikro, akan terlihat apakah kebijakan Poros Maritim Global sudah memiliki program yang cukup signifikan atau belum, sehingga dapat menjadi catatan untuk pemerintah dalam merumuskan kebijakan yang lebih baik di masa mendatang.

\section{METODOLOGI}

Penelitian ini akan menggunakan metode analisa kualitatif dengan studi kasus fokus pada analisa kekuatan (strength), kelemahan (weakness), peluang (opportunity), dan ancaman (threat) kebijakan Poros Maritim Global di wilayah Kepulauan Riau. Pola penalaran secara konseptualisasi dengan berdasarkan konsep-konsep dalam studi hubungan internasional .

Untuk mendapatkan data, teknik pengumpulan data juga digunakan dalam kajian pustaka, dengan mencari, mengumpulkan, dan mendiskusikan data sekunder yang berasal dari berbagai literatur seperti peninjauan buku, artikel, jurnal, data online, dan berita.. Sementara data primer diperoleh dari wawancara dengan koresponden serta download dokumen atau cetak biru yang diperoleh langsung dari situs web Departemen Luar Negeri Indonesia, dan Departemen Kelautan dan investasi urusan Indonesia. Untuk data primer dari Kepulauan Riau diperoleh dari database dan wawancara langsung stakeholder terkait seperti Pemprov Kepri, dan juga dengan pihak akdemisi terkait seperti Universutas Maritim Raja Ali Haji

Adapun konsep yang digunakan sebagai pisau analisis dalam penelitian ini adalah konsep geopolitik dan analina SWOT (strenght, weakness, opportunity, threat).

Konsep geopolitik merupakan konsep hubungan internasional yang menyatakan bahwa satu kawasan / geografi memegang peran yang cukup signifikan untuk menentukan arah kebijakan luar negeri satu negara. Unsur-unsur seperti lokasi, luas wilayah, iklim, topografi, demografi, sumbar daya alam, dan pemanfaatan science / teknologi menjadi sangat penting. Geopolitik melihat power satu negara dari dua sudut pandang yakni land power (Halford, 1904) dan sea power (Thayer, 1890).

Negara yang memiliki kawasan yang startegis dan potensial akan membuat kebijakan luar negeri negara yang bersangkutan menjadi cenderung berupaya untuk mengeksplore lebih dan memaksimalkan kawasan itu, dan negara tetangga juga akan berusaha untuk mendapatkan keuntungan dari wilayah tersebut, baik berupa kerjasama dengan negara pemilik kawasan maupun dengan cara-cara coersive. Seharusnya negara pemilik land power atau sea power mampu 
memanfaatkan

power

yang

dimilikinya dan memiliki posisi tawar yang bagus dalam kerjasama terkait kawasan dengan negara lain. Maka berdasarkan konsep ini, Kepulauan Riau merupakan wilayah yang tepat untuk menjadi salah satu pusat pengembangan proyek Poros Maritim Global karena memiliki lokasi maritim yang sangat startegis (sea power).

Konsep berikutnya yang digunakan adalah konsep analisa SWOT (strenght, weakness, opportunity, threat) oleh Albert Humphrey (Humphrey, 2005) dan merupakan teknik perencanaan strategis yang digunakan untuk membantu seseorang atau organisasi mengidentifikasi kekuatan, kelemahan, peluang, dan ancaman yang terkait dengan persaingan bisnis atau perencanaan proyek.

SWOT mengasumsikan bahwa kekuatan dan kelemahan sering terkait secara internal, sementara peluang dan ancaman umumnya fokus adalah karena lingkungan eksternal dengan empat parameter yakni, (1) kekuatan: karakteristik yang memberikan keuntungan; (2) kelemahan: karakteristik yang menyebabkan kerugian; (3) peluang: faktor lingkungan yang dapat dimanfaatkan; dan (4) ancaman: faktor lingkungan yang dapat menyebabkan masalah .
Sejauh mana faktor internal selaras dengan eksternal dinyatakan dirumuskan dengan konsep kesesuaian strategis. Identifikasi SWOT penting karena dapat mengetahui langkah-langkah selanjutnya dalam perencanaan untuk mencapai keuntungan kompetitif (competitive advantage)

Untuk menganalisa satu kebijakan atau proyek, dalam hal ini terkait implementasi kebijakan Poros Maritim Global di Kepulauan Riau maka parameter yang dapat diambil adalah:

Kekuatan dan kelemahan terdiri dari sumber daya manusia, sumber daya fisik, keuangan, program dan Implementasi, dan pengalaman masa lalu. Peluang dan ancaman meliputi tren masa depan, ekonomi, sumber pendanaan, demografi, lingkungan fisik, kekuatan Hukum, kerjasama lokal, nasional, atau internasional.

\section{HASIL DAN ANALISIS}

Visi Poros Maritim Global telah dijawantahkan dalam kebijakan laut Indonesia (Dewan Kelautan Indonesia, 2012) dengan tujuh pilar kebijakan, yakni:

1. Pengelolaan sumber daya kelautan dan pengembangan sumber daya manusia,

2. Pertahanan, keamanan, penegakan hukum dan 
keselamatan laut,

3. Tata kelola dan kelembagaan laut,

4. Ekonomi infrastruktur dan peningkatan kesejahteraan,

5. Pengelolaan ruang laut dan perlindungan lingkungan laut

6. Budaya bahari, dan

7. Diplomasi maritim

Serta memiliki enam prinsip kebijakan (wawasan nusantara, pembangunan berkelanjutan, ekonomi biru, pengelolaan terintegrasi dan transparan, partisipasi, serta pemerataan dan kesejahteraan) dan tujuh puluh enam kebijakan utama.

Presiden Jokowi lebih jauh menguraikan doktrin tersebut dengan pembangunan infrastruktur tol laut, industri perkapalan dan pariwisata maritim serta penerapan diplomasi maritim, baik itu peningkatan kerja sama maupun penanganan konflik maritim, seperti pencurian ikan, pelanggaran kedaulatan, sengketa wilayah dan perompakan maritim.

Kebijakan ini merupakan mega proyek yang membutuhkan dana hinga ratusan triliun rupiah untuk pembangunan 24 pelabuhan dengan total biaya sekitar 39.5 triliun rupiah, dan pembelian 609 kapal dengan total biaya sekitar 57.31 triliun rupiah (Marsetia, 2014).

Terkait implementasi di Kepulauan Riau, berdasarkan hasil analisa data sekunder dan primer disimpulkan bahwa tidak heran pemerintah menjadikan Kepulauan Riau sebagai salah satu wilayah yang ditargetkan untuk program poros martim global. Hal ini karena dari dari segi kekuatan (strenght) kawasan Kepulauan Riau khususnya Tanjung Pinang sebagai ibukota provinsi, dan Batam merupakan kota dengan pertumbuhan ekonomi dan infrastruktur yang sangat baik serta menerapkan program blue economy (ekonomi biru) dan sustainable development (pembangunan berkelanjutan).

Kawasan ini juga merupakan salah satu kota pariwisata dan pelabuhan internasional di kawasan maritim yang sangat strategis yakni berada di kawasan selat Malaka yang merupakan wilayah lintas tiga Negara yakni Indonesia, Malaysia, dan Singapura. Maka jelas kawasan ini sangat potensial untuk mendukung terwujudnya visi Indonesia menjadi poros maritim global

Namun yang menjadi kelemahan kemudian (weakness) dari kebijakan poros maritim global ini adalah belum adanya regulasi yang efektif untuk permasalahan-permasalahan makro seperti salah satunya terkait masalah tumpahan minyak yang berkepanjangan di Kepulauan Riau. Tidak hanya berdampak buruk bagi ekosistem laut, tetapi juga berdampak 
pada sektor ekonomi terpenting Kepulauan Riau yaitu wisata bahari. Selain itu juga terkait masalah pertahanan seperti di kawasan laut Cina selatan khususnya kawasan kepulauan Natuna yang hingga saat ini masih rawan konflik.

Kejahatan transnasional seperti penyelundupan (smuggling) baik orang, senjata maupun narkoba juga masih terjadi. Selain itu prosedur implementasi kebijakan yang bersifat teknis di lapangan terkait koordinasi pemerintah pusat, provinsi dan regional juga sering terjadi. Misalnya, Indonesia memiliki proses perizinan Public Private Partnership (PPP) (Siwage, 2017) yang rumit, yang mengharuskan memperoleh lebih dari 40 izin dan lisensi dari berbagai instansi pemerintah. Setiap proyek KPS perlu mengajukan izin usaha, mendapatkan persetujuan untuk spesifikasi teknis proyek, mendapatkan izin operasi, dan mendapatkan persetujuan untuk konstruksi. Selain itu, pemerintah juga tidak memiliki cukup dana untuk mewujudkan kebijakan mega proyek ini.

Meskipun demikian, kebijakan pemerintah untuk mewujudkan Indonesia sebagai poros maritim dunia dimana salah satu wilayah targetnya adalah Kepulauan Riau ini bukanlah wacana tanpa aksi. Peluang (opportunity) untuk pencapaiannya masih terbuka lebar. Sederet program untuk mewujudkannya telah dibuat diantaranya melalui program reposisi Batam sebagai pusat industri pembuatan kapal. Mengingat letak Batam yang secara geografis berdekatan dengan jalur pelayaran internasional, Pemerintah mencanangkan kebijakan untuk mendorong pertumbuhan industri galangan kapal Indonesia pada tahun 2015, yaitu melalui pemberian insentif fiskal dan nonfiskal. Insentif fiskal termasuk pengurangan pajak pertambahan nilai untuk pembuat kapal, pencairan cepat bea masuk yang dibayar pemerintah, dan struktur tarif yang berbeda untuk kapal baru dan bekas. Bantuan nonfiskal terdiri dari membantu persewaan tanah di wilayah Badan Usaha Milik Negara. $\mathrm{Hal}$ ini diperkuat dengan serangkaian langkah untuk mengkoordinasikan peran Otoritas Kawasan Perdagangan Bebas Indonesia (BP Batam) dan Pemerintah Kota Batam (Pemko Batam).

Aspek peluang (opportunity) lain dari kebijakan maritim ini adalah terkait reposisi Provinsi Kepulauan Riau sebagai pos terdepan militer yang strategis. Kebijakan tersebut bertujuan untuk menangkal potensi ancaman yang berasal dari kegiatan reklamasi lahan China di Laut China Selatan. Ini termasuk beberapa serangan oleh kapal penangkap ikan China di 
perairan Natuna, disamping untuk melindungi sumber daya alam Indonesia di jalur perairan yang strategis.

Selanjutnya pada tahun 2015, Badan Pengawas Perikanan ( PSDKP) meningkatkan pengawasan dengan bekerja sama dengan Badan Keamanan Laut Indonesia ( Bakamla ), Polisi Perairan Indonesia ( Polair), dan Angkatan Laut Indonesia ( TNI$A L$ ) terkait penangkapan ikan ilegal (illegal fishing).Dewan Perwakilan Rakyat (DPR) juga telah meratifikasi perjanjian perbatasan laut lainnya yang disepakati pada tahun 2014, meliputi sisi timur Selat Singapura.Ratifikasi tersebut memungkinkan kedua belah pihak untuk menjalankan kedaulatan masing-masing sekaligus berpotensi meningkatkan pembangunan kepercayaan.

Di level internasional. kerjasama regional terkait infrastruktur dan perdagangan seperti MPAC (Master Plan on ASEAN Connectivity ) dan IMT GT (Indonesia Malaysia Thailand Golden Triangle) (memiliki beberapa program yang terfokus di kawasan Indonesia salah satunya Kepulauan Riau (Jalur MalakaDumai). . Dan untuk pendanaan program terkait pencapaian poros martim ini, Indonesia juga bisa mendapatkan bantuan asing mengingat status Indonesia yang telah lama menjadi anggota ADB (Asian Development Bank) dan juga AIIB (Asian Infrastructure Investment Bank). Namun hal ini seperti pisau bermata dua dimana bantuan asing ini juga bisa menjadi ancaman (threat) bagi kedaulatan negara kepedapannya (debt trap diplomacy).

\section{KESIMPULAN}

Setelah menganalisa kekuatan (strength), kelemahan (weakness), peluang (opportunity), dan tantangan (threat) implementasi kebijakan Poros Marim Global di wilayah Kepulauan Riau, disimpulkan bahwa upaya pemerintah untuk mengembalikan potensi maritim Kepulauan Riau dan menjaga kedaulatan Indonesia atas perbatasan teritorialnya telah membuahkan hasil yang cukup baik namun perlu lebih ditingkatkan.

Penulis berpendapat bahwa model kebijakan dengan pola paradiplomasi atau dikenal juga dengan istilah diplomasi multi lapis (Moreno, 2016) perlu diterpakan untuk mengatasi permasalahan yang ada. Hal ini karena peran pemerintah daerah akan menjadi sangat penting dimana konsep ini tidak lagi menekankan pemerintah pusat sebagai aktor utama. Satu kebijakan akan lebih mudah untuk dicapai jika terdapat sinergitas antara pemerintah pusat dan daerah.

Setelah mendapatkan pola yang 
tepat di tataran mikro, kebijakan level makro/internasional juga perlu diperhatikan. Program Master Plan on ASEAN Connectivity misalnya merupakan wadah yang tepat untuk untuk pencapaian visi sebagai Poros Maritim Global. ASEAN merupakan "rumah" bagi Indonesia dalam tataran regional oleh karena itu penting untuk melihat bagaimana ASEAN berperan dalam mewujudkan visi Indonesia menjadi Poros Maritim Global, terlebih setelah dideklarasikannya Program Indo Pacific Outlook yang membuat ASEAN membuka peluang kerjasama dengan Negara-negara kawasan Hindia Pasifik.

\section{REFERENSI}

Al Syahrin, M. N. (2018) “Kebijakan Poros Maritim Jokowi dan Sinergitas Strategi Ekonomi dan Keamanan Laut", Indonesia Perspective, 3(1). Doi: https://doi.org/10.14710/ip.v3i1.201 75

Aufiya, A. (2017) 'Indonensia's Global Maritime Fulcrume: Contribution in The Indo- Pacific Region", Andalas Journal of International Studies, (6)2. Available at: http://ajis.fisip.unand.ac.id/index.php /ajis/article/view/74 (Diakses: 20 September 2020).

Fathun, L. M. (2017) Kebijakan geopolitik poros maritim di era Jokowi dalam filosofi frame ideologis. Jurnal PIR, 1(2), pp. 135-152. Tersedia di: http://e-journal.potensiutama.ac.id/ojs/index.php/PIR/articl e/view/389 (Diakses: 19 September 2020).
Hudaya, M \& Putra, A.T.(2017) "Toward Indonesia as Global Maritime Fulcrum: Correcting Doctrine and Combating Non-Traditional Maritime Threats", Jurnal Hubungan Internasional, 10(2), pp. $72-85$ Tersedia di: https://doi.org/10.20473/jhi.v10i2.73 04 (Diakses: 20 September 2020).

Humphrey, A. (2005) SWOT Analysis for Management Consulting. SRI Alumni Newsletter. SRI International, United States.

IDSS. (2015) Indonesia's Global Maritime Fulcrum Challenges and Trajectories. RSIS Nanyang Technological University Singapore. pp. 1-28. Tersedia di: https://www.rsis.edu.sg/event/works hop-by-indonesia-programmeidss/\#.YAEv51X7TDc (Diakses: 20 September 2020).

Laksmana, E. A., Gindarsih, I., \& Mantong, A. W. (2018) 'Menerjemahkan Visi Poros Maritim Global ke dalam Kerangka Diplomasi Pertahanan Maritim dalam Kebijakan Luar Negeri Indonesia di Era Jokowi', CSIS Working Paper, WPSINT - 01/2018, pp. 1 - 36 .

Mahan, A. T. (1890) The Influence of Sea Power Upon History 1660-1783. Little Brown and Company: Boston.

Marsetio. (2014) Sea Power Indonesia. Indonesia Defence University: Jakarta.

Mckinder, H. (1904) "The Geographical Pivot of History", The Geographical Journal, (23)4.

Negara, S.D \& Das, S.B. (2017) Challenges for Indonesia to achieve its Maritime Connectivity Plan and Leverage on Regional Initiatives ISEAS. Yusof Ishak Institute (Online). Tersedia di: https://www.iseas.edu.sg/images/pd f/ISEAS_Perspective_2017_3.pdf (Diakses: 19 September 2020). 
Saragih, H. M., Siregar, R., \& Putera, E. B.

(2018) "Indonesian National Power to

Achieve the Global Maritime

Fulcrum", Proceedings of the 5 th

International Conference on Community

Development (AMCA), 231, pp. 47-49.

Doi: https://doi.org/10.2991/amca-

18.2018.14

Tri, A. M. (2017) "Indonesia Border

Diplomacy Under The Global

Maritime Fulcrum", Ritsumeikan

International Affairs, vol. 15, pp. 45-66.

Available at:

https://www.researchgate.net/publica tion/319826875_Indonesia_Border_ Diplomacy_Under_The_Global_Mari time_Fulcrum (Diakses: 20 September 2020). 